\title{
Association between the tissue accumulation of advanced glycation end products and exercise capacity in cardiac rehabilitation patients
}

Mitsuhiro Kunimoto ${ }^{1}$, Kazunori Shimada ${ }^{1,2^{*}}$, Miho Yokoyama ${ }^{1,2}$, Tomomi Matsubara ${ }^{1}$, Tatsuro Aikawa', Shohei Ouchi ${ }^{1}$, Megumi Shimizu' ${ }^{1}$,Kosuke Fukao ${ }^{1}$, Tetsuro Miyazaki ${ }^{1}$, Tomoyasu Kadoguchi ${ }^{1}$, Kei Fujiwara ${ }^{1}$, Abidan Abulimiti', Akio Honzawa², Miki Yamada², Akie Shimada ${ }^{3}$, Taira Yamamoto ${ }^{3}$, Tohru Asai ${ }^{3}$, Atsushi Amano ${ }^{3}$, Andries J. Smit ${ }^{4}$ and Hiroyuki Daida, ${ }^{1,5}$

\begin{abstract}
Background: Advanced glycation end products (AGEs) are associated with aging, diabetes mellitus (DM), and other chronic diseases. Recently, the accumulation of AGEs can be evaluated by skin autofluorescence (SAF). However, the relationship between SAF levels and exercise capacity in patients with cardiovascular disease (CVD) remains unclear. This study aimed to investigate the association between the tissue accumulation of AGEs and clinical characteristics, including exercise capacity, in patients with CVD.

Methods: We enrolled 319 consecutive CVD patients aged $\geq 40$ years who underwent early phase II cardiac rehabilitation (CR) at our university hospital between November 2015 and September 2017. Patient background, clinical data, and the accumulation of AGEs assessed by SAF were recorded at the beginning of CR. Characteristics were compared between two patient groups divided according to the median SAF level (High SAF and Low SAF).

Results: The High SAF group was significantly older and exhibited a higher prevalence of DM than the Low SAF group. The sex ratio did not differ between the two groups. AGE levels showed significant negative correlations with peak oxygen uptake and ventilator efficiency (both $P<0.0001$ ). Exercise capacity was significantly lower in the high SAF group than in the low SAF group, regardless of the presence or absence of DM $(P<0.05)$. A multivariate logistic regression analysis showed that SAF level was an independent factor associated with reduced exercise capacity (odds ratio 2.10; 95\% confidence interval 1.13-4.05; $P=0.02$ ).

Conclusion: High levels of tissue accumulated AGEs, as assessed by SAF, were significantly and independently associated with reduced exercise capacity. These data suggest that measuring the tissue accumulation of AGEs may be useful in patients who have undergone $C R$, irrespective of whether they have DM.
\end{abstract}

Keywords: Advanced glycation end products, Exercise tolerance, Cardiac rehabilitation, Skin autofluorescence

\footnotetext{
* Correspondence: shimakaz@juntendo.ac.jp

'Department of Cardiovascular Medicine, Juntendo University Graduate

School of Medicine, 2-1-1 Hongo, Bunkyo-ku, Tokyo 113-8421, Japan

${ }^{2}$ Cardiovascular Rehabilitation and Fitness, Juntendo University Hospital, 2-1-1

Hongo, Bunkyo-ku, Tokyo 113-8421, Japan

Full list of author information is available at the end of the article
}

C C The Author(s). 2020 Open Access This article is licensed under a Creative Commons Attribution 4.0 International License, which permits use, sharing, adaptation, distribution and reproduction in any medium or format, as long as you give appropriate credit to the original author(s) and the source, provide a link to the Creative Commons licence, and indicate if changes were made. The images or other third party material in this article are included in the article's Creative Commons licence, unless indicated otherwise in a credit line to the material. If material is not included in the article's Creative Commons licence and your intended use is not permitted by statutory regulation or exceeds the permitted use, you will need to obtain permission directly from the copyright holder. To view a copy of this licence, visit http://creativecommons.org/licenses/by/4.0/. The Creative Commons Public Domain Dedication waiver (http://creativecommons.org/publicdomain/zero/1.0/) applies to the data made available in this article, unless otherwise stated in a credit line to the data. 


\section{Background}

Exercise intolerance is recognized to be an important predictor of adverse outcomes in patients with cardiovascular disease (CVD) [1-3]. Previous studies demonstrated higher mortality rates in patients with heart failure (HF) with reduced exercise capacity (EC), especially in those with peak oxygen uptake (peak $\mathrm{VO}_{2}$ ) $\leq 14 \mathrm{~mL} / \mathrm{kg} / \mathrm{min}$ [4-7].

Advanced glycation end products (AGEs) are harmful compounds formed when proteins, lipids, and nucleic acids combine with glucose [8]. AGEs accumulate in the body as a result of aging, food intake, and smoking. The reactions that result in AGE accumulation are accelerated under hyperglycemic conditions such as those caused by diabetes mellitus (DM), and in inflammatory conditions, and oxidative stress $[9,10]$. AGEs have been shown to directly crosslink proteins, including vascular and muscle collagen, which alters the protein structure and results in dysfunction $[8,11]$. Previous studies of the relationship between AGEs and physical function reported that populations with high concentrations of the AGE carboxymethyllysine are more likely to exhibit decreased grip strength and slower walking speed [12, 13].

Skin autofluorescence (SAF) has recently been developed as an accurate and noninvasive method to measure AGE accumulation in the skin. SAF has received attention as its results can provide a useful predictor of allcause mortality and cardiovascular mortality in patients who are high-risk [14-16].

Evidence that supports that the accumulation of AGEs may be associated with reduced EC exists but whether SAF levels are associated with reduced EC in patients with CVD remains unclear. Thus, the aim of this study was to investigate the association between SAF levels and clinical characteristics in patients with CVD and to evaluate the relationship between SAF levels and EC.

\section{Methods \\ Study population}

This retrospective cross-sectional study included 371 consecutive patients who underwent cardiopulmonary exercise testing (CPX) at the beginning of phase II cardiac rehabilitation (CR) at our university hospital between November 2015 and September 2017. Of these, 18 patients were excluded for being aged < 40 years, 34 were excluded because of a lack of SAF data. The final study population consisted of 319 patients (Fig. 1). Written informed consent was provided by all the patients prior to participation. The study protocol was approved by the ethical committee of our institution, and the study was conducted in accordance with the principles of the Helsinki Declaration.

\section{Skin autofluorescence}

SAF levels were measured with an AGE Reader (DiagnOptics Technologies B.V., Groningen, Netherlands) [17]. This noninvasively evaluates the accumulation of AGEs in the skin by measuring the level of fluorescence with light excitation [18]. SAF levels were calculated as the ratio of the average light intensity in the 420-600 $\mathrm{nm}$ wavelength range and the average excitation light intensity in the 300-420 nm range. A previous study has shown that AGEs bind and accumulate to collagen and elastin in the epithelium and dermis [19]. A study of healthy and diabetic subjects confirmed that SAF levels

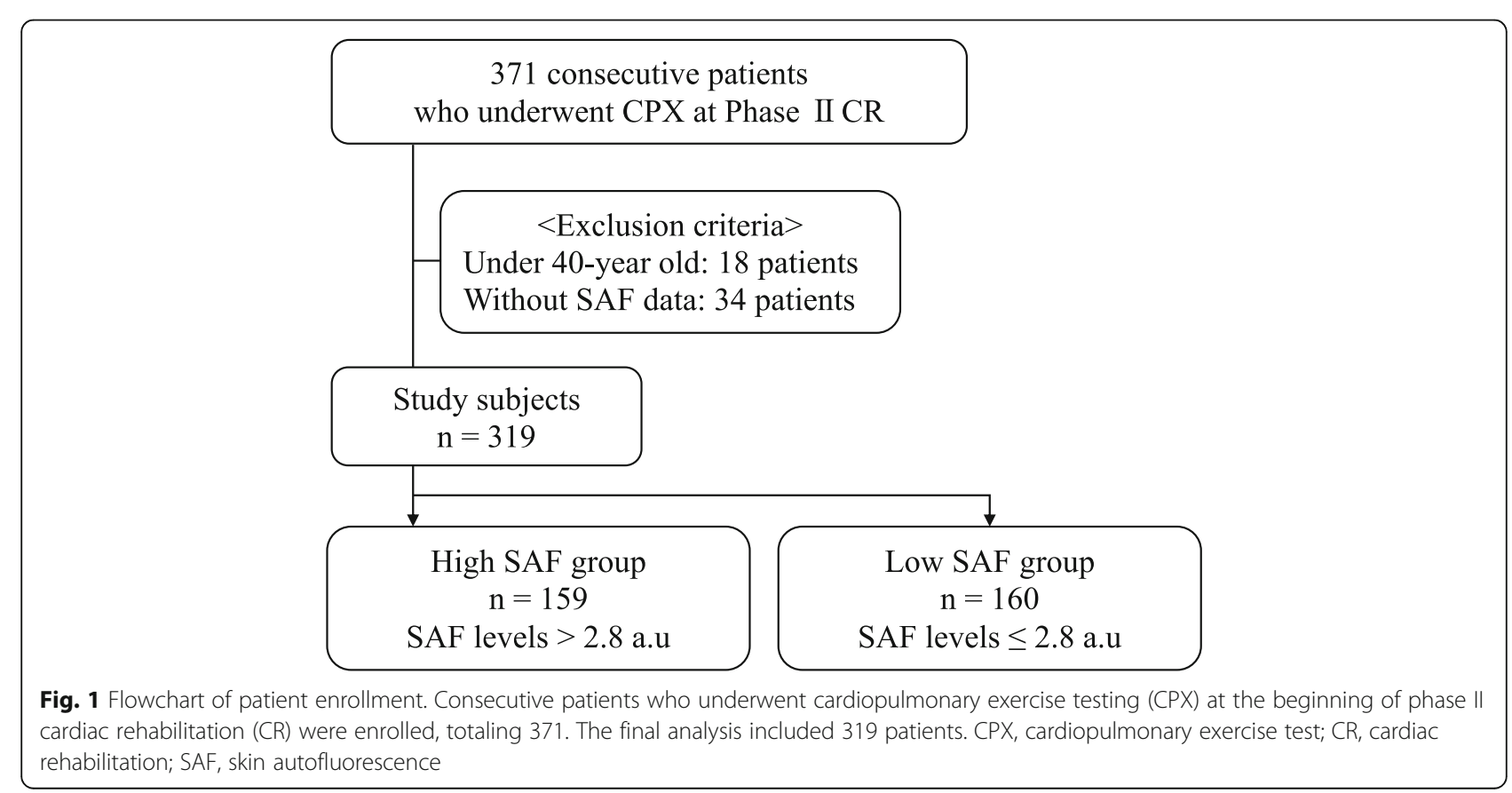


assessed by the AGE Reader correlated well with skin biopsy assessments of the accumulation of AGEs such as pentosidine and carboxymethyllysine [20]. Thus, SAF levels provide an indication of the accumulation of AGEs in the epithelium and dermis of the skin. In the present study, SAF was measured from the inside of the forearm while the patient was seated.

\section{Data collection}

Age, sex, smoking history, comorbidities, and medical history were obtained from the patients' medical records. Blood samples were collected in the early morning after overnight fasting. A diagnosis of DM was defined by hemoglobin $\mathrm{A} 1 \mathrm{c} \geq 6.5 \%$ or by receiving treatment for DM. Chronic kidney disease (CKD) was defined as an estimated glomerular filtration rate $(\mathrm{eGFR})<60 \mathrm{~mL} /$ $\mathrm{min} / 1.73 \mathrm{~m} 2$, calculated by the renal disease equation with the Japanese coefficient, using baseline serum creatinine and modification to diet [21].

\section{Measurements}

Body composition, grip strength, SAF level, and EC were assessed at the beginning of CR. Anthropometric parameters, including the percentage of body fat, lean body weight, and muscle mass, were measured by bioelectrical impedance analysis (TANITA, MC-780A, Tokyo, Japan), as described previously $[22,23]$. Grip strength was tested in both hands with the patient in a standing position; the higher of the two grip strength values was used in the analysis. EC was assessed by CPX on a cycle ergometer (Strength Ergo 8, Mitsubishi Electric Corp., Tokyo, Japan) with an expiratory gas analysis machine (AE-310S, Minato Medical Science Co., Ltd., Osaka, Japan). A ramp protocol was used with a workload increase of $10 \mathrm{~W} / \mathrm{min}$ to measure the anaerobic threshold and peak $\mathrm{VO}_{2}$. Heart rate was recorded continuously using a standard 12-lead electrocardiogram, and blood pressure was registered every minute during the exercise testing. Peak $\mathrm{VO}_{2}$ was defined as the highest $\mathrm{VO}_{2}$ value recorded during $\mathrm{CPX}$. The anaerobic threshold point was determined by the $\mathrm{V}$-slope method, as previously described [24]. Patients with a peak $\mathrm{VO}_{2} \leq 14$ $\mathrm{mL} / \mathrm{kg} / \mathrm{min}$ were categorized as having reduced EC; the other patients were classified as having non-reduced EC.

\section{Statistical analysis}

Continuous variables are presented as mean \pm standard deviation. Comparisons between groups were evaluated using Welch's t test for continuous variables and the chisquared test for categorical variables. Logistic regression models were used to examine relationships between reduced EC and other factors. We selected covariates with significant differences determined as such by the comparison between the reduced EC and nonreduced EC groups to input into the multivariate analysis. Differences were considered statistically significant at $P<0.05$. JMP version 12.0 (SAS Institute, Cary, NC, USA) was used to perform the statistical analyses.

\section{Results}

Baseline characteristics and SAF data

In 319 subjects enrolled in the present study, mean age was $66 \pm 12$ years old, and 256 patients were male (80.3\%). Figure 2 shows the distribution of SAF levels. The values of mean and median SAF levels were $2.9 \pm 0.6$ a.u and 2.8 a.u (interquartile range: $2.5,3.2$ a.u), respectively.

\section{Comparison between the high SAF and low SAF groups}

The patients were divided into two groups based on the median value of SAF. The High and Low SAF groups comprised 159 and 160 participants, respectively. Table 1 compares the clinical characteristics between the two groups. There was no significant difference in sex ratio. Compared to the Low SAF group, the High SAF group exhibited a significantly higher mean age, higher mean body fat percentage, and higher prevalence of DM, CKD, and a history of coronary artery bypass grafting. Cardiac function defined as systolic and diastolic function was similar between the two groups. Hemoglobin and albumin levels were significantly lower in the High SAF group than in the Low SAF group, whereas HbA1c was significantly higher. The anaerobic threshold and peak $\mathrm{VO}_{2}$ of the High SAF group were significantly lower than those of the Low SAF group (both $P<0.01$ ).

\section{Comparison between the diabetes and non-diabetes groups}

The patients were divided into two groups by DM status and then classified as high or low SAF according to the median SAF level for the group (3.0 a.u. for the DM group and 2.7 a.u. for the non-DM group). Comparisons of the clinical characteristics between the high and low SAF subgroups tended to show the same trends in the DM and non-DM groups (Supplemental Tables 1 and 2). In the DM group, peak $\mathrm{VO}_{2}$ was significantly lower in the high SAF subgroup than in the low SAF subgroup $(14.5 \pm 3.1$ vs. $16.1 \pm 3.9 \mathrm{~mL} /$ $\mathrm{kg} / \mathrm{min}$, respectively; $P<0.05)$. Similarly, in the non-DM group, peak $\mathrm{VO}_{2}$ was significantly lower in the high SAF subgroup compared to the low SAF subgroup $(16.4 \pm 3.5$ vs. $17.5 \pm 3.8 \mathrm{~mL} / \mathrm{kg} / \mathrm{min} ; \mathrm{P}<0.05$ ) (Fig. 3).

\section{Association between SAF levels and reduced EC}

Reduced EC is considered to be clinically important [4-7]. Therefore, we performed a logistic regression analysis to investigate the factors that were independently associated with reduced EC, defined as peak $\mathrm{VO}_{2} \leq 14 \mathrm{~mL} / \mathrm{kg} / \mathrm{min}$ (Supplemental Table 3 shows the comparisons of the clinical characteristics between the reduced and non-reduced EC groups). After adjusting for age, sex, BMI, DM, Atrial 


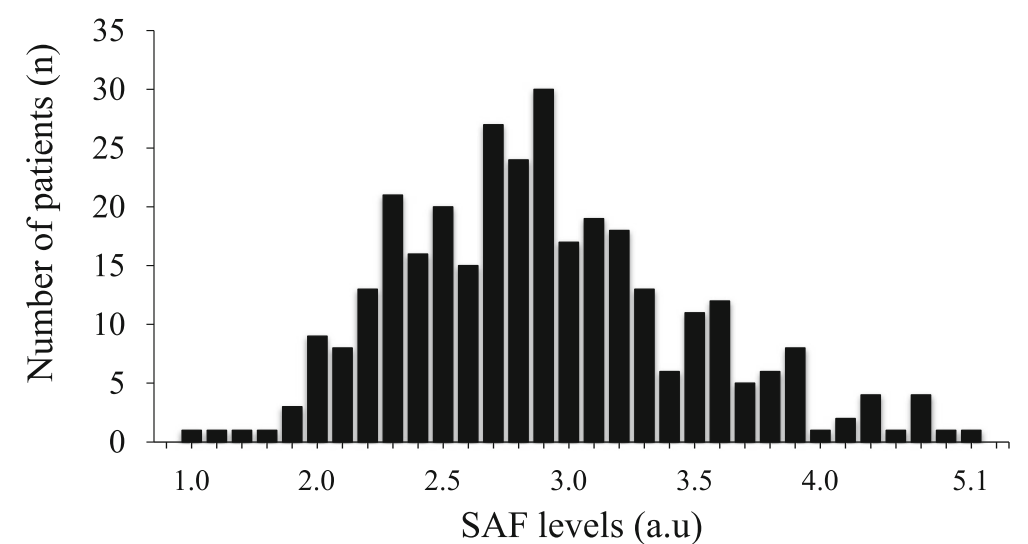

Fig. 2 Distribution of SAF levels. The values of mean and median SAF levels were $2.9 \pm 0.6$ a.u and 2.8 a.u (interquartile range: $2.5,3.2$ a.u), respectively. Shapiro-Wilk test of normality: $P<0.05$. SAF, skin autofluorescence; DM, diabetes mellitus

fibrillation, body fat percentage, E/e', albumin, eGFR, HDL-cholesterol, BNP, aspirin and SAF, SAF level was found to be a significant independent factor associated with reduced EC (odds ratio 2.10, 95\% confidence interval 1.13-4.05; $P=0.02$ ) (Table 2).

\section{Discussion}

The results of this study showed that EC was significantly lower in patients with higher SAF levels regardless of their DM status and that SAF levels were independently associated with reduced EC, even while cardiac systolic and diastolic function were similar between both groups. To the best of our knowledge, this is the first study to demonstrate an association between SAF levels and reduced EC among patients with CVD who underwent CR.

Several studies reported an association between plasma AGEs and lower physical function in community-dwelling elderly people $[12,13]$. In addition, a study of a Japanese population reported that SAF levels were significantly higher in the study group with lower muscle mass (defined by the Asian Working Group for Sarcopenia's skeletal muscle mass index criteria) and were a significant independent factor associated with low skeletal muscle index values [17]. The results of the present study further confirm the relationship between SAF levels and reduced EC. This is an important finding because impaired EC is known to be a powerful predictor of poor prognosis [1-3]. A previous study of patients with HF with systolic dysfunction reported that SAF level were significantly higher and EC was significantly lower in patients with DM than in those without DM [25]. In addition, the patients with SAF levels above the mean value demonstrated lower EC [25]. Our findings are consistent with those of the previous report, and we additionally found that patients with higher SAF levels demonstrated significantly lower EC, even in the patients without DM.
It has been reported that patients with DM showed reduced muscle function and EC [26-28]. Although the determinants of impaired physical function in patients with DM are poorly understood, several mechanisms have been proposed [29]. Previous studies demonstrated an inverse correlation between EC measured by peak $\mathrm{VO}_{2}$ and insulin resistance, and that increased SAF levels were positively associated with insulin resistance in patients with DM [30-32]. It has also been reported that serum AGE levels were positively correlated with insulin resistance even in non-DM patients [33]. Furthermore, previous studies reported that diabetes and hyperglycemia are associated with mitochondrial dysfunction and increased levels of mitochondrial reactive oxygen species in the vasculature, resulting in endothelial nitric oxide synthase inhibition [34, 35]. In addition to these direct effects, AGEs can bind with AGE receptors, which can result in endothelial dysfunction and the enhanced production of reactive oxygen species [36]. Animal experiments suggested that endothelial nitric oxide could be a factor in EC regulation [34-37]. Crosslinking of myocardial collagen with AGEs may contribute to increased myocardial stiffness and diastolic dysfunction [11, 36]. In addition, left ventricular diastolic dysfunction due to DM is associated with decreased left ventricular compliance, resulting in a restricted ability to increase cardiac output during exercise, thereby limiting EC $[38,39]$. Previous studies have reported that diastolic dysfunction assessed by E/e' is a strong predictor of exercise intolerance, and this association was independent of DM [40, 41]. Consistent with these studies, our investigation demonstrated that E/e' was one of the significant factors influencing reduced EC. In the present study, age was also associated with reduced EC. It has been suggested that the effects of aging on exercise intolerance are due in part to decreased activity and changes in body composition [42]. Moreover, the accumulation of AGEs has also 
Table 1 Patient characteristics

\begin{tabular}{|c|c|c|c|}
\hline & High SAF $(n=159)$ & Low $\operatorname{SAF}(n=160)$ & $P$ value \\
\hline Age & $67.9 \pm 10.4$ & $60.6 \pm 11.8$ & $<0.01$ \\
\hline Male (\%) & $127(79.9)$ & $129(80.6)$ & 0.87 \\
\hline BMI & $23.7 \pm 3.5$ & $23.3 \pm 3.3$ & 0.38 \\
\hline Diabetes mellitus (\%) & $69(43.4)$ & $38(23.8)$ & $<0.01$ \\
\hline Hypertension (\%) & $107(67.3)$ & $102(63.8)$ & 0.51 \\
\hline Dyslipidemia (\%) & $86(54.1)$ & $86(53.8)$ & 0.95 \\
\hline Chronic kidney disease (\%) & $46(28.9)$ & $28(17.6)$ & 0.02 \\
\hline Current smoking (\%) & $22(13.8)$ & $22(13.8)$ & 1 \\
\hline COPD (\%) & $14(8.8)$ & $5(3.1)$ & 0.03 \\
\hline Cancer (\%) & $0(0)$ & $3(1.9)$ & 0.21 \\
\hline \multicolumn{4}{|l|}{ History of CVD } \\
\hline MI (\%) & $19(12.0)$ & $16(10.0)$ & 0.58 \\
\hline $\mathrm{PCl}(\%)$ & $34(21.4)$ & $22(13.8)$ & 0.07 \\
\hline CABG (\%) & $9(5.7)$ & $6(3.8)$ & 0.41 \\
\hline Valvular surgery (\%) & $10(6.3)$ & $6(3.8)$ & 0.29 \\
\hline CHF (\%) & $32(20.1)$ & $27(16.9)$ & 0.45 \\
\hline \multicolumn{4}{|l|}{$C V D$ at the beginning of $C R$} \\
\hline Acute myocardial infarction (\%) & $20(12.6)$ & $19(11.9)$ & 0.85 \\
\hline Effort angina pectoris (\%) & $28(17.6))$ & $20(12.5)$ & 0.20 \\
\hline $\mathrm{PCl}(\%)$ & $28(17.6)$ & $25(15.6)$ & 0.63 \\
\hline CABG (\%) & $45(28.3)$ & $24(15.0)$ & $<0.01$ \\
\hline Valvular disease (\%) & $58(36.5)$ & $59(36.9)$ & 0.94 \\
\hline Valvular surgery (\%) & $47(29.8)$ & $50(31.3)$ & 0.77 \\
\hline Aortic disease (\%) & $10(6.3)$ & $13(8.1)$ & 0.53 \\
\hline Peripheral artery disease (\%) & $8(5.0)$ & $3(1.9)$ & 0.12 \\
\hline Atrial fibrillation (\%) & $24(15.1)$ & $26(16.3)$ & 0.78 \\
\hline \multicolumn{4}{|l|}{ Anthropometric data } \\
\hline Body fat percentage (\%) & $23.4 \pm 7.7$ & $21.4 \pm 8.5$ & 0.03 \\
\hline Lean body weight $(\mathrm{kg})$ & $48.6 \pm 8.4$ & $50.1 \pm 8.7$ & 0.13 \\
\hline Trunk muscle mass (kg) & $24.8 \pm 3.9$ & $25.7 \pm 4.2$ & 0.06 \\
\hline Upper limb muscle mass (kg) & $4.6 \pm 1.0$ & $4.8 \pm 1.0$ & 0.15 \\
\hline Lower limb muscle mass (kg) & $16.6 \pm 4.0$ & $17.1 \pm 3.5$ & 0.32 \\
\hline Grip strength (kg) & $29.9 \pm 8.2$ & $32.3 \pm 8.4$ & 0.04 \\
\hline \multicolumn{4}{|l|}{ Echocardiography } \\
\hline LVEF (\%) & $56 \pm 14$ & $57 \pm 15$ & 0.74 \\
\hline$E / A$ & $1.3 \pm 0.9$ & $1.4 \pm 0.9$ & 0.42 \\
\hline$E / e^{\prime}$ & $14.1 \pm 0.7$ & $13.0 \pm 0.7$ & 0.28 \\
\hline \multicolumn{4}{|l|}{ Laboratory data } \\
\hline Hemoglobin (g/dL) & $13.3 \pm 1.9$ & $13.9 \pm 1.7$ & $<0.01$ \\
\hline Albumin (g/dL) & $3.9 \pm 0.4$ & $4.0 \pm 0.5$ & 0.03 \\
\hline Creatinine $(\mathrm{mg} / \mathrm{dL})$ & $1.11 \pm 1.4$ & $0.8 \pm 0.3$ & $<0.01$ \\
\hline $\mathrm{eGFR}\left(\mathrm{mL} / \mathrm{min} / 1.73 \mathrm{~m}^{2}\right)$ & $70.1 \pm 25.7$ & $77.2 \pm 19.4$ & $<0.01$ \\
\hline $\mathrm{TG}(\mathrm{mg} / \mathrm{dL})$ & $114 \pm 63$ & $130 \pm 87$ & 0.07 \\
\hline HDL cholesterol (mg/dL) & $49 \pm 15$ & $50 \pm 16$ & 0.68 \\
\hline
\end{tabular}


Table 1 Patient characteristics (Continued)

\begin{tabular}{|c|c|c|c|}
\hline & High $\operatorname{SAF}(n=159)$ & Low $\operatorname{SAF}(n=160)$ & $P$ value \\
\hline LDL cholesterol (mg/dL) & $100 \pm 28$ & $100 \pm 30$ & 0.88 \\
\hline $\mathrm{HbA1c}(\%)$ & $6.1 \pm 0.8$ & $5.8 \pm 0.6$ & $<0.01$ \\
\hline BNP $(p g / n L)$ & $200.6 \pm 516.0$ & $160 \pm 287$ & 0.40 \\
\hline Skin autofluorescence (a.u) & $3.3 \pm 0.4$ & $2.4 \pm 0.3$ & $<0.01$ \\
\hline \multicolumn{4}{|l|}{ Medication } \\
\hline Aspirin (\%) & $130(82.3)$ & $12(78.1)$ & 0.35 \\
\hline ACE-I/ARB (\%) & $66(41.8)$ & $62(38.8)$ & 0.58 \\
\hline Statin (\%) & $106(67.1)$ & $87(54.4)$ & 0.02 \\
\hline$\beta$ blocker (\%) & $116(73.4)$ & $116(72.5)$ & 0.85 \\
\hline Ca antagonist (\%) & $29(18.4)$ & $21(13.1)$ & 0.20 \\
\hline Loop diuretics (\%) & $110(69.6)$ & $108(67.5)$ & 0.68 \\
\hline Oral hypoglycemic agent (\%) & $35(22.2)$ & $13(8.1)$ & $<0.01$ \\
\hline Insulin (\%) & $14(8.9)$ & $0(0)$ & $<0.01$ \\
\hline \multicolumn{4}{|l|}{ Anaerobic threshold (AT) } \\
\hline Workload (W) & $43 \pm 14$ & $49 \pm 15$ & $<0.01$ \\
\hline AT $(\mathrm{mL} / \mathrm{kg} / \mathrm{min})$ & $10.7 \pm 2.2$ & $11.8 \pm 2.5$ & $<0.01$ \\
\hline \multicolumn{4}{|l|}{ Peak exercise } \\
\hline $\mathrm{HR}(/ \min )$ & $111 \pm 19$ & $116 \pm 20$ & 0.03 \\
\hline $\mathrm{SBP}(\mathrm{mmHg})$ & $178 \pm 30$ & $173 \pm 31$ & 0.16 \\
\hline $\mathrm{DBP}(\mathrm{mmHg})$ & $86 \pm 17$ & $87 \pm 17$ & 0.41 \\
\hline RER & $1.12 \pm 0.11$ & $1.11 \pm 0.10$ & 0.18 \\
\hline Workload (W) & $77 \pm 20$ & $86 \pm 21$ & $<0.01$ \\
\hline Peak VO ${ }_{2}(\mathrm{~mL} / \mathrm{kg} / \mathrm{min})$ & $15.6 \pm 3.5$ & $17.2 \pm 3.8$ & $<0.01$ \\
\hline VENCOO & $32.4 \pm 7.5$ & $29.5 \pm 6.5$ & $<0.01$ \\
\hline
\end{tabular}

High SAF; defined as SAF levels $>2.8$

Data are presented as the mean value \pm SD. BMI body mass index, COPD chronic obstructive pulmonary disease, CVD cardiovascular disease, MI myocardial infarction, $P C I$ percutaneous coronary intervention, $C A B G$ coronary artery bypass graft, $C H F$ congestive heart failure, $C R$ cardiac rehabilitation, $L V$ left ventricular, $E F$ ejection fraction, $E$ early diastolic filling velocity, $A$ late diastolic filling velocity, $e^{\prime}$ early diastolic tissue velocity, eGFR estimate glomerular filtration rate, $T G$ triglyceride, $H D L$ high-density lipoprotein cholesterol, $L D L$ low-density lipoprotein cholesterol, $H b A 1 c$ hemoglobin A1c, $B N P B$-type natriuretic peptide, $H R$ heart rate, $S B P$ systolic blood pressure, $D B P$ diastolic blood pressure, $R E R$ respiratory exchange ratio, peak $V_{2}$ peak oxygen uptake

\section{DM patients}

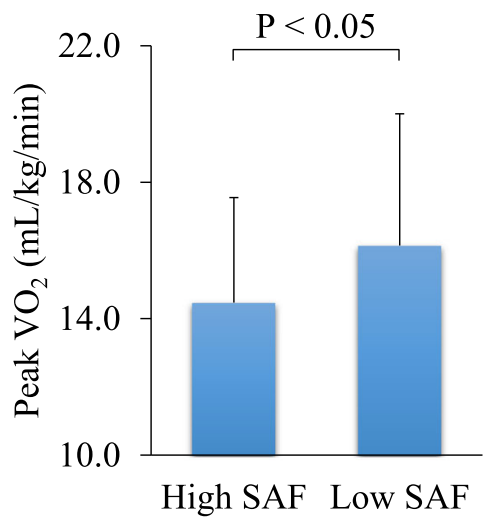

non DM patients

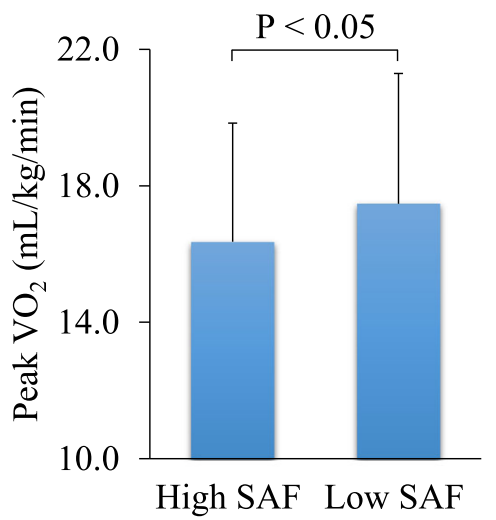

Fig. 3 Comparison of peak oxygen uptake $\left(\mathrm{VO}_{2}\right)$ levels between the High ( $>2.8$ a.u.) and low ( $\leq 2.8$ a.u.) SAF groups. Regardless of the presence or absence of $\mathrm{DM}$, peak $\mathrm{VO}_{2}$ levels were significantly lower in the high SAF group than in the low SAF group. SAF, skin autofluorescence; DM, diabetes mellitus 
Table 2 Logistic regression analysis of reduced EC

\begin{tabular}{|c|c|c|c|c|c|c|}
\hline \multirow[t]{2}{*}{ Variables } & \multicolumn{3}{|l|}{ Univariate } & \multicolumn{3}{|l|}{ Multivariate } \\
\hline & Odds ratio & $95 \% \mathrm{Cl}$ & $P$ value & Odds ratio & $95 \% \mathrm{Cl}$ & $P$ value \\
\hline Age & 1.05 & $1.03-1.08$ & $<0.01$ & 1.04 & $1.00-1.09$ & 0.04 \\
\hline Female & 1.82 & $1.01-3.22$ & $<0.05$ & 0.97 & $0.31-2.96$ & 0.96 \\
\hline BMl & 1.08 & $1.01-1.17$ & $<0.05$ & 0.98 & $0.83-1.15$ & 0.76 \\
\hline Diabetes mellitus & 2.64 & $1.61-4.38$ & $<0.01$ & 1.56 & $0.74-3.26$ & 0.24 \\
\hline Atrial fibrillation & 3.99 & $2.15-7.52$ & $<0.01$ & 1.48 & $0.55-3.90$ & 0.43 \\
\hline Albumin & 0.45 & $0.26-0.77$ & $<0.01$ & 1.22 & $0.56-2.72$ & 0.62 \\
\hline eGFR & 0.97 & $0.96-0.99$ & $<0.01$ & 0.99 & $0.97-1.01$ & 0.18 \\
\hline BNP & 1.00 & $1.00-1.002$ & $<0.01$ & 1.00 & $0.99-1.00$ & 0.73 \\
\hline$E / e^{\prime}$ & 1.06 & $1.02-1.10$ & $<0.01$ & 1.05 & $1.00-1.10$ & 0.04 \\
\hline Body fat percentage & 1.09 & $1.05-1.13$ & $<0.01$ & 1.07 & $0.99-1.16$ & 0.054 \\
\hline HDL cholesterol & 0.98 & $0.96-0.99$ & $<0.05$ & 0.98 & $0.96-1.01$ & 0.14 \\
\hline Aspirin & 0.46 & $0.26-0.83$ & $<0.01$ & 0.57 & $0.20-1.63$ & 0.29 \\
\hline SAF & 2.63 & $1.72-4.13$ & $<0.01$ & 2.10 & $1.13-4.05$ & 0.02 \\
\hline
\end{tabular}

EC exercise capacity, $C l$ confidence interval, $B M I$ body mass index, eGFR estimate glomerular filtration rate, BNP B-type natriuretic peptide, $E$ early diastolic filling velocity, $e^{\prime}$ early diastolic tissue velocity, HDL high density lipoproteins, SAF skin autofluorescence

been observed to be associated with aging, lifestyle habits such as specific food intake, and smoking, in addition to the presence of chronic inflammatory conditions such as metabolic syndrome, arteriosclerosis, and renal disease $[9,10,43]$. The deterioration of EC with AGE accumulation may, therefore, be the result of AGEs causing the functional decline of several organ systems that regulate EC, regardless of DM status. A recent meta-analysis demonstrated that SAF levels were a predictor of mortality in high-risk patients [15]. This could potentially be explained by the association between high SAF levels and reduced EC observed in the present study. As for interventions, a recent study reported that alagebrium, proposed as an AGE-breaker, did not ameliorate EC and cardiac function, but also failed to lower SAF levels in patients with HF [44]. Thus, further studies are needed to elucidate the mechanisms by which AGEs affect EC.

Body fat percentage also tended to have an effect on reduced EC in the present study. Although interactions between AGEs and adipocytes have not been fully clarified [45], the accumulation of body fat may relate to deterioration in insulin sensitivity, increased intracellular lipids in skeletal muscle, and the decreased metabolic ability of mitochondria, ultimately resulting in decreased oxygen intake during exercise [46-49].

This study exhibits several limitations. First, this was a single-center and retrospective cross-sectional study with a small sample size, so we could not establish a causal relationship between SAF level and reduced EC. Second, we enrolled patients with CVD who underwent CR. Third, the method of SAF assessment did not measure the total accumulation of all AGEs in the body. Fourth, SAF represents not only the fluorescence values resulting from skin AGEs, but also from other fluorophores such as keratin, therefore assessment of SAF may not be an accurate measurement of the skin's AGE content [50]. Fifth, previous studies suggest that the reliability of AGE analysis in skin may depend on skin color, as this affects the skin's tendency to absorb excitation light [51]. Sixth, SAF is strongly influenced by the use of skin creams, which leads to elevated SAF values and decreased skin reflectance [52]. Seventh, SAF is a surrogate marker of tissue accumulation of AGEs. Whether skin AGEs reflect the accumulation of AGEs in cardiac tissue is an important question, and further investigations are needed to answer it. Finally, the diagnosis of DM may have been underestimated because some patients did not undergo an oral glucose tolerance test.

\section{Conclusion}

In conclusion, this study demonstrated that high levels of tissue accumulated AGEs, as assessed by SAF, were significantly and independently associated with reduced EC. These data suggest that the measurement of the tissue accumulation of AGEs may be useful for patients undergoing $\mathrm{CR}$, including those without DM. Further studies should be carried out to determine whether elevated SAF levels are a specific predicter of decline in EC in patients undergoing $\mathrm{CR}$ and to corroborate these findings in other patients with CVD.

\section{Supplementary information}

Supplementary information accompanies this paper at https://doi.org/10. 1186/s12872-020-01484-3.

Additional file 1: Table S1. Comparison of clinical characteristics between High SAF (> 3.0 a. u.) and Low SAF ( $\leq 3.0$ a.u.) groups in DM (diabetes mellitus) patients. 
Additional file 2: Table S2. Comparison of clinical characteristics between (> 2.7 a.u.) and Low SAF ( $\leq 2.7$ a.u.) groups in non DM (diabetes mellitus) patients.

Additional file 3: Table S3. Comparison of clinical characteristics between reduced EC and non-reduced EC groups.

\section{Abbreviations}

CVD: Cardiovascular disease; HF: Heart failure " EC: Exercise capacity; AGEs: Advanced glycation end products; DM: Diabetes mellitus; SAF: Skin autofluorescence; CPX: Cardiopulmonary exercise testing; CR: Cardiac rehabilitation; CKD: Chronic kidney disease.

\section{Acknowledgments}

The authors wish to thank all study participants and members of date collection in Cardiovascular Rehabilitation and Fitness.

\section{Authors' contributions}

MK, KS, MY1, and HD contributed to the conception and design of the work. AJS, KF1 and TM2 contributed to the conception of the work. MK, KS and MY1 contributed to the acquisition, analysis, and interpretation of data for the work. TM1, MS, KF2, AH, MY2, AS, TA2, TY and AA2 contributed to the acquisition of data for the work. TA1, SO, TK and AA1 contributed to the interpretation of data for the work. MK drafted the manuscript. All authors critically revised the manuscript. All gave final approval and agree to be accountable for all aspects of work ensuring integrity and accuracy.

\section{Funding}

This study was supported in part by JSPS KAKENHI Grant Number 17 K01470 and the High Technology Research Center Grant from the Ministry of Education, Culture, Science, and Technology, Japan. The funding body had no role in the design of the study and collection, analysis, and interpretation of data and in writing the manuscript.

\section{Availability of data and materials}

The datasets used and/or analysed during the current study are available from the corresponding author on reasonable request.

\section{Ethics approval and consent to participate}

Approval was received from the Juntendo University and authorization for the usage of medical records was obtained. The study protocol was approved by the ethical committee of Juntendo University Hospital, and the study was conducted in accordance with the principles of the Helsinki Declaration. Written informed consents from all patients enrolled were obtained.

\section{Consent for publication}

Not Applicable.

\section{Competing interests}

A.J. Smit is co-founder and shareholder of Diagnoptics Technologies, the company which developed the AGE reader. The other authors declare that they have no competing interests.

\section{Author details}

${ }^{1}$ Department of Cardiovascular Medicine, Juntendo University Graduate School of Medicine, 2-1-1 Hongo, Bunkyo-ku, Tokyo 113-8421, Japan. ${ }^{2}$ Cardiovascular Rehabilitation and Fitness, Juntendo University Hospital, 2-1-1 Hongo, Bunkyo-ku, Tokyo 113-8421, Japan. ${ }^{3}$ Department of Cardiovascular Surgery, Juntendo University Graduate School of Medicine, 2-1-1 Hongo, Bunkyo-ku, Tokyo 113-8421, Japan. ${ }^{4}$ Division of Vascular Medicine, Department of Internal Medicine, University of Groningen, University Medical Center Groningen, Hanzeplein 1, Groningen 9713 GZ, Netherlands. ${ }^{5}$ Faculty of Health Science, Juntendo University, 2-1-1 Hongo, Bunkyo-ku, Tokyo 113-8421, Japan.
Received: 8 November 2019 Accepted: 14 April 2020

Published online: 23 April 2020

\section{References}

1. Vanhees L, Fagard R, Thijs L, Staessen J, Amery A. Prognostic significance of peak exercise capacity in patients with coronary artery disease. J Am Coll Cardiol. 1994;23(2):358-63.

2. Leeper NJ, Myers J, Zhou M, Nead KT, Syed A, Kojima Y, et al. Exercise capacity is the strongest predictor of mortality in patients with peripheral arterial disease. J Vasc Surg. 2013;57(3):728-33.

3. Myers J, Prakash M, Froelicher V, Do D, Partington S, Atwood JE. Exercise capacity and mortality among men referred for exercise testing. N Engl J Med. 2002;346(11):793-801.

4. Mancini DM, Eisen H, Kussmaul W, Mull R, Edmunds LH Jr, Wilson JR. Value of peak exercise oxygen consumption for optimal timing of cardiac transplantation in ambulatory patients with heart failure. Circulation. 1991; 83(3):778-86.

5. Gitt AK, Wasserman K, Kilkowski C, Kleemann T, Kilkowski A, Bangert M, et al. Exercise anaerobic threshold and ventilatory efficiency identify heart failure patients for high risk of early death. Circulation. 2002;106(24):3079-84.

6. Osada N, Chaitman BR, Miller LW, Yip D, Cishek MB, Wolford TL, et al. Cardiopulmonary exercise testing identifies low risk patients with heart failure and severely impaired exercise capacity considered for heart transplantation. J Am Coll Cardiol. 1998;31(3):577-82.

7. Zugck C, Haunstetter A, Kruger C, Kell R, Schellberg D, Kubler W, et al. Impact of beta-blocker treatment on the prognostic value of currently used risk predictors in congestive heart failure. J Am Coll Cardiol. 2002;39(10):1615-22.

8. Brownlee M. Biochemistry and molecular cell biology of diabetic complications. Nature. 2001;414(6865):813-20.

9. Prasad K, Dhar I, Caspar-Bell G. Role of advanced Glycation end products and its receptors in the pathogenesis of cigarette smoke-induced cardiovascular disease. Int J Angiol. 2015;24(2):75-80.

10. Vlassara $\mathrm{H}$, Uribarri J. Advanced glycation end products (AGE) and diabetes: cause, effect, or both? Curr Diab Rep. 2014;14(1):453.

11. Kovacic JC, Castellano JM, Farkouh ME, Fuster V. The relationships between cardiovascular disease and diabetes: focus on pathogenesis. Endocrinol Metab Clin N Am. 2014;43(1):41-57.

12. Dalal M, Ferrucci L, Sun K, Beck J, Fried LP, Semba RD. Elevated serum advanced glycation end products and poor grip strength in older communitydwelling women. J Gerontol A Biol Sci Med Sci. 2009;64(1):132-7.

13. Semba RD, Bandinelli S, Sun K, Guralnik JM, Ferrucci L. Relationship of an advanced glycation end product, plasma carboxymethyl-lysine, with slow walking speed in older adults: the InCHIANTI study. Eur J Appl Physiol. 2010; 108(1):191-5.

14. Yamagishi S, Fukami K, Matsui T. Evaluation of tissue accumulation levels of advanced glycation end products by skin autofluorescence: a novel marker of vascular complications in high-risk patients for cardiovascular disease. Int J Cardiol. 2015:185:263-8.

15. Cavero-Redondo I, Soriano-Cano A, Alvarez-Bueno C, Cunha PG, MartinezHortelano JA, Garrido-Miguel M, et al. Skin autofluorescence-indicated advanced Glycation end products as predictors of cardiovascular and allcause mortality in high-risk subjects: a systematic review and meta-analysis. J Am Heart Assoc. 2018;7(18):e009833.

16. van Waateringe RP, Fokkens BT, Slagter SN, van der Klauw MM, van VlietOstaptchouk JV, Graaff R, et al. Skin autofluorescence predicts incident type 2 diabetes, cardiovascular disease and mortality in the general population. Diabetologia. 2019;62(2):269-80.

17. Kato M, Kubo A, Sugioka Y, Mitsui R, Fukuhara N, Nihei F, et al. Relationship between advanced glycation end-product accumulation and low skeletal muscle mass in Japanese men and women. Geriatr Gerontol Int. 2017;17(5):785-90.

18. Meerwaldt R, Graaff R, Oomen PHN, Links TP, Jager JJ, Alderson NL, et al. Simple non-invasive assessment of advanced glycation endproduct accumulation. Diabetologia. 2004:47(7):1324-30.

19. Gkogkolou P, Bohm M. Advanced glycation end products: key players in skin aging? Dermatoendocrinol. 2012;4(3):259-70.

20. Lutgers HL, Graaff R, Links TP, Ubink-Veltmaat LJ, Bilo HJ, Gans RO, et al. Skin autofluorescence as a noninvasive marker of vascular damage in patients with type 2 diabetes. Diabetes Care. 2006;29(12):2654-9.

21. Matsuo S, Imai E, Horio M, Yasuda Y, Tomita K, Nitta K, et al. Revised equations for estimated GFR from serum creatinine in Japan. Am J Kidney Dis. 2009;53(6):982-92 
22. Nishitani M, Shimada K, Masaki M, Sunayama S, Kume A, Fukao K, et al. Effect of cardiac rehabilitation on muscle mass, muscle strength, and exercise tolerance in diabetic patients after coronary artery bypass grafting. J Cardiol. 2013;61(3):216-21.

23. Nishitani-Yokoyama M, Miyauchi K, Shimada K, Yokoyama T, Ouchi S, Aikawa $T$, et al. Impact of physical activity on coronary plaque volume and components in acute coronary syndrome patients after early phase II cardiac rehabilitation. Circ J. 2018;83(1):101-9.

24. Kunimoto M, Shimada K, Yokoyama M, Matsubara T, Aikawa T, Ouchi S, et al. Relationship between the Kihon checklist and the clinical parameters in patients who participated in cardiac rehabilitation. Geriatr Gerontol Int. 2019;19(4):287-92.

25. Willemsen S, Hartog JW, Hummel YM, van Ruijven MH, van der Horst IC, van Veldhuisen DJ, et al. Tissue advanced glycation end products are associated with diastolic function and aerobic exercise capacity in diabetic heart failure patients. Eur J Heart Fail. 2011;13(1):76-82.

26. Park SW, Goodpaster BH, Strotmeyer ES, de Rekeneire N, Harris TB, Schwartz AV, et al. Decreased muscle strength and quality in older adults with type 2 diabetes: the health, aging, and body composition study. Diabetes. 2006; 55(6):1813-8.

27. Kunitomi M, Takahashi K, Wada J, Suzuki H, Miyatake N, Ogawa S, et al. Reevaluation of exercise prescription for Japanese type 2 diabetic patients by ventilatory threshold. Diabetes Res Clin Pract. 2000;50(2):109-15.

28. Nishitani M, Shimada K, Sunayama S, Masaki Y, Kume A, Fukao K, et al. Impact of diabetes on muscle mass, muscle strength, and exercise tolerance in patients after coronary artery bypass grafting. J Cardiol. 2011;58(2):173-80.

29. Reusch JE, Bridenstine M, Regensteiner JG. Type 2 diabetes mellitus and exercise impairment. Rev Endocr Metab Disord. 2013;14(1):77-86.

30. Nadeau KJ, Zeitler PS, Bauer TA, Brown MS, Dorosz JL, Draznin B, et al. Insulin resistance in adolescents with type 2 diabetes is associated with impaired exercise capacity. J Clin Endocrinol Metab. 2009;94(10):3687-95.

31. Nadeau KJ, Regensteiner JG, Bauer TA, Brown MS, Dorosz JL, Hull A, et al. Insulin resistance in adolescents with type 1 diabetes and its relationship to cardiovascular function. J Clin Endocrinol Metab. 2010;95(2):513-21.

32. Uruska A, Gandecka A, Araszkiewicz A, Zozulinska-Ziolkiewicz D. Accumulation of advanced glycation end products in the skin is accelerated in relation to insulin resistance in people with type 1 diabetes mellitus. Diabet Med. 2019;36(5):620-5.

33. Tahara N, Yamagishi S, Matsui T, Takeuchi M, Nitta Y, Kodama N, et al. Serum levels of advanced glycation end products (AGEs) are independent correlates of insulin resistance in nondiabetic subjects. Cardiovasc Ther. 2012;30(1):42-8.

34. Knaub LA, McCune S, Chicco AJ, Miller M, Moore RL, Birdsey N, et al. Impaired response to exercise intervention in the vasculature in metabolic syndrome. Diab Vasc Dis Res. 2013;10(3):222-38.

35. Srinivasan S, Hatley ME, Bolick DT, Palmer LA, Edelstein D, Brownlee M, et al. Hyperglycaemia-induced superoxide production decreases eNOS expression via AP-1 activation in aortic endothelial cells. Diabetologia. 2004;47(10):1727-34.

36. Hegab Z, Gibbons S, Neyses L, Mamas MA. Role of advanced glycation end products in cardiovascular disease. World J Cardiol. 2012;4(4):90-102.

37. Maxwell AJ, Schauble E, Bernstein D, Cooke JP. Limb blood flow during exercise is dependent on nitric oxide. Circulation. 1998;98(4):369-74.

38. Fang ZY, Sharman J, Prins JB, Marwick TH. Determinants of exercise capacity in patients with type 2 diabetes. Diabetes Care. 2005;28(7):1643-8.

39. Kitzman DW, Higginbotham MB, Cobb FR, Sheikh KH, Sullivan MJ. Exercise intolerance in patients with heart failure and preserved left ventricular systolic function: failure of the frank-Starling mechanism. J Am Coll Cardiol. 1991;17(5):1065-72.

40. Grewal J, McCully RB, Kane GC, Lam C, Pellikka PA. Left ventricular function and exercise capacity. JAMA. 2009;301(3):286-94.

41. Fontes-Carvalho R, Sampaio F, Teixeira M, Rocha-Gonçalves F, Gama V, Azevedo $A$, et al. Left ventricular diastolic dysfunction and E/E' ratio as the strongest echocardiographic predictors of reduced exercise capacity after acute myocardial infarction. Clin Cardiol. 2015:38(4):222-9.

42. Hawkins $S$, Wiswell R. Rate and mechanism of maximal oxygen consumption decline with aging:implications for exercise training. Sports Med. 2003;33(12):877-88

43. Luevano-Contreras C, Gomez-Ojeda A, Macias-Cervantes MH, Garay-Sevilla ME. Dietary advanced Glycation end products and Cardiometabolic risk. Curr Diab Rep. 2017;17(8):63.
44. Hartog JW, Willemsen S, van Veldhuisen DJ, Posma JL, van Wijk LM, Hummel YM, et al. Effects of alagebrium, an advanced glycation endproduct breaker, on exercise tolerance and cardiac function in patients with chronic heart failure. Eur J Heart Fail. 2011;13(8):899-908.

45. Boyer F, Vidot JB, Dubourg AG, Rondeau P, Essop MF, Bourdon E. Oxidative stress and adipocyte biology: focus on the role of AGEs. Oxidative Med Cell Longev. 2015;2015:534873.

46. Stewart KJ. Exercise training and the cardiovascular consequences of type 2 diabetes and hypertension: plausible mechanisms for improving cardiovascular health. JAMA. 2002;288(13):1622-31.

47. Ribisl PM, Lang W, Jaramillo SA, Jakicic JM, Stewart KJ, Bahnson J, et al. Exercise capacity and cardiovascular/metabolic characteristics of overweight and obese individuals with type 2 diabetes: the look AHEAD clinical trial. Diabetes Care. 2007;30(10):2679-84.

48. Wei M, Gibbons LW, Kampert JB, Nichaman MZ, Blair SN. Low cardiorespiratory fitness and physical inactivity as predictors of mortality in men with type 2 diabetes. Ann Intern Med. 2000;132(8):605-11.

49. Rovira-Llopis S, Banuls C, Diaz-Morales N, Hernandez-Mijares A, Rocha M, Victor VM. Mitochondrial dynamics in type 2 diabetes: pathophysiological implications. Redox Biol. 2017;11:637-45.

50. Koetsier M, Nur E, Chunmao H, Lutgers HL, Links TP, Smit AJ, et al. Skin color independent assessment of aging using skin autofluorescence. Opt Express. 2010;18(14):14416-29.

51. Mulder DJ, Water TV, Lutgers HL, Graaff R, Gans RO, Zijlstra F, et al. Skin autofluorescence, a novel marker for glycemic and oxidative stress-derived advanced glycation endproducts: an overview of current clinical studies, evidence, and limitations. Diabetes Technol Ther. 2006;8(5):523-35.

52. Noordzij MJ, Lefrandt JD, Graaff R, Smit AJ. Dermal factors influencing measurement of skin autofluorescence. Diabetes Technol Ther. 2011;13(2): $165-70$.

\section{Publisher's Note}

Springer Nature remains neutral with regard to jurisdictional claims in published maps and institutional affiliations.

Ready to submit your research? Choose BMC and benefit from

- fast, convenient online submission

- thorough peer review by experienced researchers in your field

- rapid publication on acceptance

- support for research data, including large and complex data types

- gold Open Access which fosters wider collaboration and increased citations

- maximum visibility for your research: over $100 \mathrm{M}$ website views per year

At BMC, research is always in progress.

Learn more biomedcentral.com/submissions 